\title{
Aplicaciones de la programación lineal
}

\author{
Linear Programming Applications \\ Francisca Santana Robles ${ }^{a}$
}

\begin{abstract}
:
Linear programming is an area of mathematics called "optimization techniques". It is a technique that allows to maximize or minimize a linear function subject to several restrictions. Its area of application is very broad, since it can be used to solve problems of various disciplines such as: finance, economics, marketing, logistics, production systems, transport systems, among others. At present, there is a different type of software that facilitates the solution of linear models with a large number of variables, which allows to address more complex problems in different disciplines.
\end{abstract}

\section{Keywords:}

Programming linear, optimization techniques, operations research

\section{Resumen:}

La programación lineal es un área de las matemáticas denominada "técnicas de optimización". Es una técnica que permite maximizar o minimizar una función lineal sujeta a varias restricciones. Su área de aplicación es muy amplia, puesto que, se puede utilizar para resolver problemas de diversas disciplinas como son: finanzas, economía, mercadotecnia, logística, sistemas de producción, sistemas de transporte, entre otras. Actualmente, existe en el mercado diferente tipo de software que facilita la solución de modelos lineales con una gran cantidad de variables, lo que permite abordar problemas más complejos en las diferentes disciplinas.

\section{Palabras Clave:}

Programación lineal, técnicas de optimización, investigación de operaciones

\section{Introducción}

La programación lineal es una técnica de optimización matemática que permite maximizar o minimizar una función lineal. Es una técnica muy útil para resolver problemas que impliquen maximizar beneficios o minimizar costos; optimizando el uso de los recursos. Es usada en diferentes disciplinas (finanzas, economía, mercadotecnia, logística, entre otras) y en diferentes tipos de industrias como son: manufacturera, petrolera, química, alimenticia, de la construcción, entre otras. El presente mapa muestra ejemplos de problemas que pueden ser abordados con programación lineal.

\section{Descripción}

La programación lineal permite abordar diferentes tipos de problemas en diversas áreas y disciplinas. La figura 1 muestra de manera esquemática algunos ejemplos de problemas que pueden solucionarse con esta técnica. En finanzas, pueden abordarse situaciones como distribución de capital, gestión de carteras de inversión, planeación financiera y portafolios de inversión. En planeación de la producción e inventarios, pueden estudiarse situaciones como programación de la producción, optimización de niveles de inventario, asignación de recursos, modelos de planeación agregada, entre otros.

${ }^{a}$ Autor de Correspondencia, Universidad Autónoma del Estado de Hidalgo, Escuela Superior de Ciudad Sahagún, https://orcid.org/0000- 
En asignación de tareas, problemas como asignación de horarios, asignación de trabajos y planeación de mano de obra. Por otra parte, en mercadotecnia, pueden resolverse situaciones como selección de medios publicitarios y estudios de marcado. Por su parte, en mezclas la programación lineal se usa para la optimización de diferentes materias primas en la fabricación de productos. En logística, es una técnica muy útil para la optimización de costos de transporte, programación de rutas, planeación de desarrollo humano, ubicación óptima de plantas, entre otros.

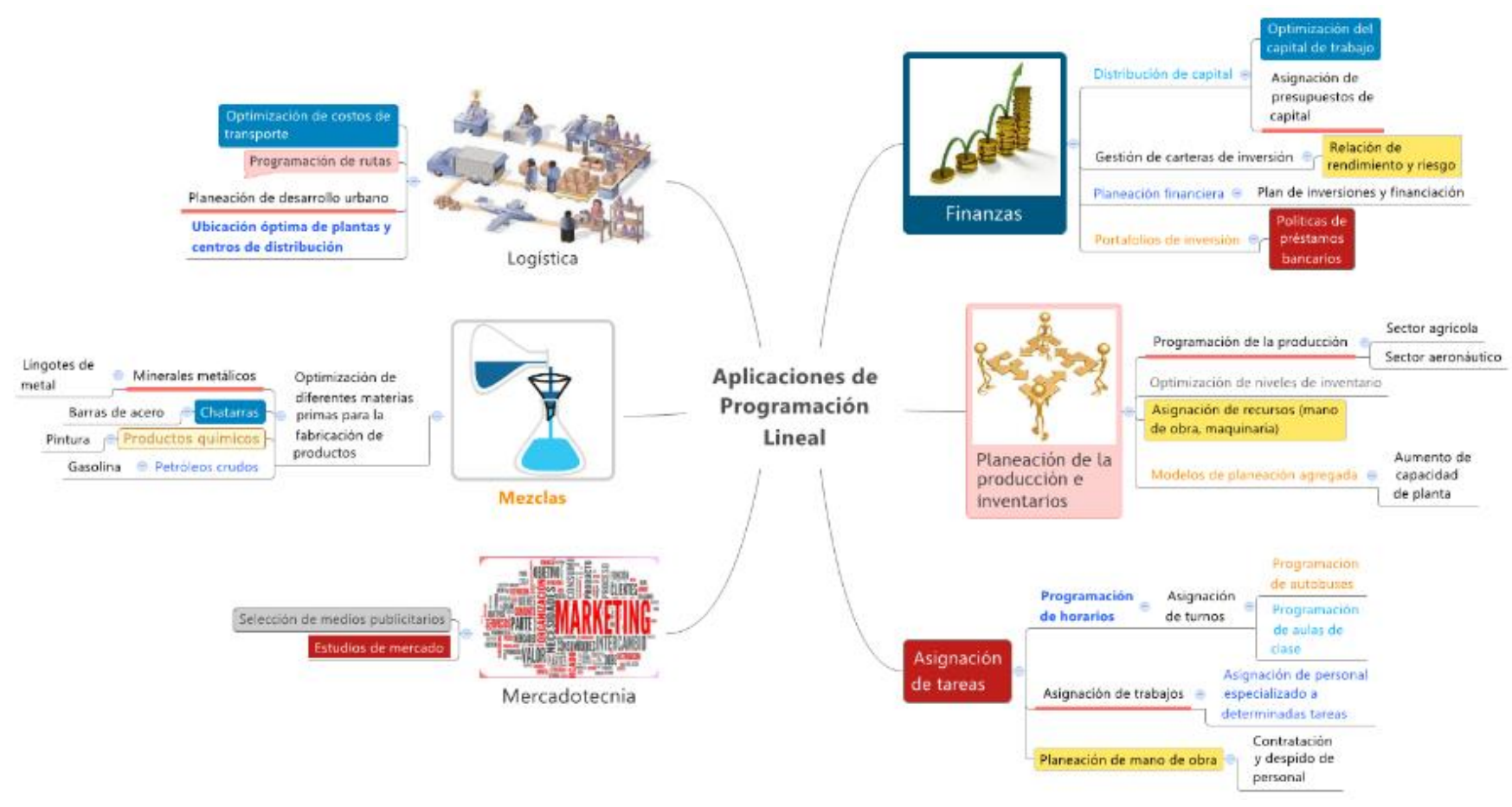

Figura 1. Aplicaciones de la programación lineal

\section{Referencias}

[1] Taha H. A. Investigación de operaciones, novena edición, México: Pearson; 2012.

[2] Bazaraa M. S., Jarvis J.J. y Sherali H. D. Programación lineal y flujo en redes, segunda edición, México: Limusa; 2011.

[3] Hillier F. S. y Liberman G. J. Introducción a la investigación de operaciones, novena edición, México: McGraw-Hill; 2010. 